\title{
Del exilio al reino: los personajes de Albert Camus \\ en busca de su felicidad
}

\author{
Caroline CASET \\ Universidad Nacional Autónoma de México
}

\begin{abstract}
En L'Exil et le royaume, La Chute y L'Étranger, los personajes de Albert Camus están conscientes de lo absurdo de vivir en un mundo ilusorio; son hombres y mujeres despiertos según las filosofías orientales como la de Buda. A partir del momento en que intuyen que existe otro mundo, buscan su yo interior. Para lograrlo, empiezan por marginarse del mundo y aislarse en la soledad. Toda la obra de Camus es un constante diálogo con Fedor Dostoievski, sobre todo con Le Rêve d'un homme ridicule. La marginalidad del protagonista ruso anónimo de este cuento evoca el exilio interior de los personajes camusianos. Algunos encuentran su paz interior y su felicidad en la solidaridad humana. En efecto, la otredad es la clave del encuentro consigo mismo. Si el hombre es capaz de amar al otro, accede entonces al reino de la fraternidad.
\end{abstract}

Palabras ClaVe: Camus, Dostoievski, otredad, busca del yo, fraternidad.

In L'Exil et le royaume, La Chute and L'Étranger, the characters of Albert Camus are aware of the absurdity of living in this world of illusion; they are awake men and women according to eastern philosophy as Buda's one. When they appraise the existence of another world, they look for their Self, marginalizing themselves of the rest of the world. All Camus' work is a constant dialogue with Fyodor Dostoyevsky, especially with Le Reve d'un homme ridicule. The marginalization of the Russian protagonist of this short story reminds the interior exile of the Camusian characters. Some of them find their Self and their own happiness in human solidarity. Undoubtfully, the bound with otherness is the key to find oneself. If man is able to love the other, then he access to the brotherhood's kingdom.

KEY WORDS: Camus, Dostoyevsky, otherness, quest of oneself, brotherhood.

Según Albert Camus, los grandes novelistas son novelistas filósofos. En un primer rango coloca al ruso Fedor Dostoievski, cuyas temáticas se encuentran de manera recurrente en la obra camusiana. Después de un largo periodo de divorcio entre la literatura y la filosofía moral, asistimos desde más o menos los años noventa a su reconciliación. Por supuesto, este divorcio nunca existió para Camus porque, como lo explica la escritora y filósofa irlandesa Iris Murdoch (Magee: 282), la novela siempre contiene un cuestionamiento moral que trasciende el ensayo filosófico por dar vida al incons- 
ciente de los personajes que luchan entre el bien y el mal. Por su parte, Paul Ricœur (167) concibe no sólo la experiencia sino también la identidad humana misma como esencialmente narrativas. Es precisamente lo que hace Albert Camus a través de su obra novelesca: escribe su historia, la transforma a través de las historias de sus personajes, a fin de encontrarse a sí mismo. De hecho, el "primer Camus" inicia una reflexión filosófica a través de personajes como sujetos morales solitarios. ¿Solitario o solidario?, escribe Jonas, el protagonista camusiano del cuento "Jonas ou l'artiste au travail". Ésa es la problemática de los relatos de L'Exil et le Royaume, l'Étranger y La Chute: cuál es el destino de los personajes camusianos en estas obras, comparándolos con el personaje de una novela breve de Dostoievski titulada Le Rêve d'un homme ridicule. Así, se tratará primero del exilio filosófico basado en el sentimiento del absurdo de estos personajes y, segundo, se mostrará cómo, de relato en relato, encuentran su yo interior y su reino perdido, aspirando a la solidaridad humana.

\section{El Cristo y el Buda: personajes exiliados en su propia sociedad}

\section{El absurdo de vivir en un mundo ilusorio: el despertar del hombre}

Jonas en el cuento "l'artiste au travail", d'Arrast en "La pierre qui pousse", Janine en "La femme adultère", Meursault en L'Étranger y Clamence en La Chute tienen en común ser exiliados en su propia sociedad, en su cultura de pertenencia. Son extranjeros como lo indica el título de la famosa novela. El sentido de "extranjero" o "exiliado" se entiende aquí por la toma de conciencia de los protagonistas que la vida es absurda, falsificada por las convenciones sociales hipócritas, tal como lo denuncia Camus con el juicio de Meursault en L'Étranger. El hecho de ser auténtico, de no mentirse a sí mismo, de no fingir en una sociedad hipócrita le hace al personaje camusiano definitivamente diferente de los otros y, por ende, incomprendido. Según la interpretación de Jacqueline Baishanski, Meursault nunca penetra por completo en este mundo como si quisiera poder escapar hacia otro, invisible pero coherente y unificado que tendría sentido, un mundo que Meursault intuye que existe (Baishanski: 170-172). En L'Étranger, este mundo invisible es evocado por "les senteurs de l'été" o por pensamientos como éste: "Je me suis réveillé avec des étoiles sur le visage. Des bruits de campagne montaient jusqu'à moi. Des odeurs de nuit, de terre et de sel rafraichissaient mes tempes. La merveilleuse paix de cet été endormi entrait en moi comme une marée" (Camus, L'Étranger: 185). Janine en "La femme adultère" intuye también otro mundo a través del paisaje desértico argelino: "Devant elle, les étoiles tombaient une à une, puis s'éteignaient parmi les pierres du désert, et à chaque fois Janine s'ouvrait un peu plus à la nuit. Elle respirait, elle oubliait le froid, le poids des êtres, la vie démente ou figée, la longue angoisse de vivre et de mourir" (Camus, L'Exil: 34). No es gratuita la imagen común de las estrellas que se acercan al personaje solitario, inspirado por las constelaciones a imaginar otro mundo. 
Toda la obra de Camus es un constante diálogo con Dostoievski, sobre todo con Le Rêve d'un homme ridicule. La marginalidad del protagonista ruso anónimo, que a partir de ahora llamaremos "el hombre ridículo", viene del hecho de que "todo le da igual", es indiferente a todo y a todos; hasta al grito desesperado de una niña miserable que le pide ayudar a su madre moribunda. Esta marginalidad se expresa con el sentimiento de sentirse ridiculo, y por ende, diferente de los otros. El "hombre ridículo" de Dostoievski dice que de golpe se convenció de que todo en el mundo le era indiferente. El narrador explica: “J'ai senti, d'un coup, que ça me serait égal qu'il y ait un monde ou qu'il n'y ait rien nulle part. Je me suis mis à entendre et à sentir par tout mon être qu'il n'y avait rien de mon vivant... À partir de ce moment, d'un coup, j'ai cessé d'en vouloir aux hommes, et je ne les ai presque plus remarqués" (Dostoievski: 13). No cabe duda que Meursault comparte las mismas impresiones y convicciones. El punto en común entre el "hombre ridículo" y Meursault, Clamence, Jonas, Janine y d'Arrast es que para cada personaje existe un momento más o menos preciso que le cambia toda su percepción de la vida. Es lo que Jacqueline Baishanski (177) llama "el choque" y que, según ella, le da otro estatuto al personaje, el estatuto de hombre despierto. Es el inicio de la transformación del personaje novelesco en sujeto moral tal como lo definen Aline Giroux (Du personnage) o Paul Ricœur (Soi-mêmes), entre otros. El choque para Meursault es cuando abandona sus estudios y deja de ser ambicioso. Para Jonas ocurre cuando lee un artículo de prensa que lo retrata como un pintor deplorable después de haber sido exaltado por la misma prensa. Jonas, entonces, despierta tal como Clamence después de haber visto a la mujer caer en el río y escuchado la risa misteriosa. No se puede criticar a la sociedad desde el interior porque ello supone que uno participa del sistema y no puede vislumbrar sus perversiones. Hay que pertenecer al margen para poder detectarlas. En efecto, Meursault, Jonas y Clamence en un momento dado frecuentan barrios marginales de la ciudad, como para desprenderse del "centro". Estas visitas les permiten admirar con mayor claridad sus vidas. Meursault trata con delincuentes, Jonas con prostitutas y Clamence con los marineros de los suburbios de Ámsterdam. En cuanto a Janine, al alcanzar las puertas del desierto argelino, cuando penetra en espacios vacíos y aislados, le da la impresión de que algo la esperaba, algo que nunca había imaginado antes en la rutina de su pequeña y aburrida vida en la ciudad.

Para los personajes camusianos, pertenecer al margen significa también que son extranjeros porque no ven la vida de la misma manera que sus compatriotas. Poseen la intuición de otro mundo, un mundo invisible, soñado, o simplemente la voluntad de escapar de lo absurdo de este mundo que definimos como real. El "hombre ridículo" de Dostoievski es muy conmovedor cuando se dirige a Dios:

Qui que Tu sois, mais si Tu es, et s'il y a quelque chose de plus raisonnable que ce qui arrive en ce moment, permets aussi que cela soit ici. Mais si tu châties mon suicide déraisonnable par une existence qui se poursuivrait dans la monstruosité et dans l'absurde, sache que jamais, et quelles que soient les tortures qui me seraient infligées, 
rien ne pourra se comparer à ce mépris que je ressentirais sans dire un mot, et même si mon martyre dure des millions d'années!... (Dostoievski: 31 ).

\section{La influencia de las filosofias orientales en ciertas obras de Camus: el hombre despierto en busca de su yo}

Todos estos personajes están en un proceso de búsqueda de su yo para alcanzar su felicidad. Piensan que existe una verdad oculta que es la llave de la felicidad humana. El "hombre ridículo" de Dostoievski sostiene que ha visto la verdad en su sueño de otro mundo, un mundo de paz y armonía. Sin embargo, es el único en haberlo contemplado y, como al Cristo, nadie lo cree. Precisamente, Camus compara a Meursault con Cristo, "el único que nos merecemos", según él (Baishanski: 13). De la misma manera, Jean-Baptiste Clamence evoca al nombre de Juan Batista, el profeta del Evangelio. Otro personaje de Camus tiene nombre de profeta: Jonas, el artista trabajando. Jonas, para buscar la verdad, se aleja del mundo, es decir, de la gente hipócrita que lo admira como pintor, invadiendo su casa y hasta su propia cama. Desde entonces, Jonas entra en su yo interior, construyendo un taller escondido bajo el techo de su casa, que le permite ser invisible a los otros. Pierre Grouix indica que la temática de La Chute, la del reino perdido, es la misma que la del conjunto de cuentos titulado L'Exil et le Royaume. En efecto, los personajes de esta recopilación muchas veces han perdido su inocencia y se sienten angustiados. Por eso se encuentran, según Pierre Grouix, en una situación "d'exil qui peut leur permettre d'accéder à un royaume quand ils sont tant en quête de leur identité que d'une fraternité difficile..." (302).

Según Carole Auroy, la figura del profeta, de Cristo, en la obra de Camus, sirve para proponer un "modèle de vie, modèle d'attitude aussi face à la mort" (441). Se trata entonces de una vida humana ejemplar, sin creer en la resurrección de Cristo; es decir que Camus propone más bien una religión humana. Eso nos lleva a considerar la interpretación de Jacqueline Baishanski, la cual está desarrollada en su libro L'Orient dans la pensée du jeune Camus: l'Étranger, un nouvel Évangile? La tesis de este libro es que el personaje de Meursault se puede comparar por varios aspectos con estos hombres excepcionales que propusieron a la humanidad filosofías orientales, tales como el budismo y el taoísmo. En efecto, Meursault se observa a sí mismo y su entorno con mucha honestidad y precisión, lo que corresponde al método budista para aprender a conocerse a sí mismo. Lo hace hasta tal punto que experimenta el efecto de desdoblamiento. Por ejemplo, durante el juicio, Meursault tiene conciencia del efecto que produce en su auditorio. El efecto de desdoblamiento es impactante cuando Meursault habla del periodista que está ante él: "et j'ai eu l'impression bizarre d'être regardé par moi-même” (Camus, L'Étranger: 132). Se siente incomprendido y prefiere callarse, como Buda que tiene conciencia de algo más alto de lo que siente la gente común y, por ende, no cree prudente revelar todo lo que sabe a sus discípulos. Así se podría explicar por qué, durante el juicio, Meursault no quiere decir nada para 
defenderse. Entonces, según Baishanski (199-201), en vez de no tener conciencia, como muchos críticos lo han dicho, Meursault tiene una conciencia superior, como la de Buda. La mayoría de las filosofías de Asia nos avisan que mientras más impersonal se torna el hombre, más siente la presencia de dos hombres en él, más unificado se vuelve. De este modo encuentra su yo.

Baishanski explica que el concepto de hombre despierto es asiático en el sentido en el que el despierto es negación. Negar es un enfoque común en Asia. En el texto de Camus, negar significa renunciar a sí mismo y a todas las cosas de este mundo para alcanzar una paz interior. Para Aline Giroux, en Du personnage romanesque au sujet moral. La littérature comme autre de la philosophie, el concepto de despertar es necesario en el proceso de construcción del personaje literario como sujeto moral. Ello explica por qué el sujeto en devenir siempre es extranjero en su cultura de origen: el personaje debe tomar distancia respecto de los valores dominantes de su propia cultura para poder empezar a liberarse, y para eso necesita ser fiel a sí mismo (Giroux: 99). Según mi opinión, eso explica por qué Meursault muestra tanta honestidad y precisión en elegir y rectificar cada palabra de su relato: tiene que ser fiel a sí mismo para "être ce que l'on est déjà', como dice Aline Giroux. Ella retoma la explicación de Hannah Arendt según la cual el sujeto debe ser autónomo para poder coexistir en la sociedad. En el mundo moderno, ya no hay ni esfera privada ni esfera pública. Por eso los individuos no tienen nada que los separe y no pueden vincularse con los otros, más bien, chocan entre ellos.

Es muy distinto el caso de los invitados, quienes están separados por una mesa, la cual simboliza el mundo. Gracias a ella, las personas pueden convivir y relacionarse. "L'union n'est parfaite que si tous ceux qui sont unis sont isolés" (Ralph Waldo Emerson, cit. en Giroux: 100).

Todo eso permite interpretar por qué la problemática de los cuentos L'Exil et le Royaume, La Chute, L'Étranger y Le Rêve d'un homme ridicule, entre otros, consiste en el dilema entre ser solitario y solidario, lo que el cuento "Jonas ou l'artiste au travail" ilustra perfectamente.

\section{II. ¿Solitario o solidario? La dificultad de relacionarse con los otros}

\section{Misión del artista y otredad}

El cuento "Jonas ou l'artiste au travail”" es obviamente alegórico y metafórico. El pintor se ha vuelto famoso sin haber realmente empezado a pintar. Esta circunstancia lo hace sentir exiliado de sí mismo. Demasiada gloria mata en él la capacidad de crear. El juicio de los otros hacia él y su incapacidad de comprenderlo son el origen de su drama interior tanto como el de todos los protagonistas del L'Exil et le Royaume o de L'Étranger. No pueden modificar el juicio de los otros. Así, cuando Jonas entiende que la opinión pública es hipócrita, se siente exiliado y se aleja físicamente de la 
gente que le devoraba hasta su vida interior (simbolizada por su cama, donde se sentaban los visitantes). A partir de ese momento, el pintor intuye otro mundo o verdad, invisible para los demás. Tiene conciencia de vivir algo que no puede compartir con ellos porque no se puede compartir una vida interior. Jonas, como Meursault, experimenta el efecto de desdoblamiento tan necesario a la reconciliación interior del ser, porque, por primera vez en su vida, toma conciencia de sus contradicciones internas. En este caso, se trata en particular del desdoblamiento del artista y evoca a Camus, quien se esforzaba por mirarse a sí mismo en pleno acto creativo. Como lo recuerda Baishanski, Camus había escrito en sus Carnets: "L'intellectuel est celui qui se dédouble. Ça me plaît. Je suis content d'être deux" (cit. en Baishanski: 197). Hay que ser dos para escribir, piensa Camus. ¿No es lo que hace Jonas cuando se refugia en la soledad de su buhardilla bajo el techo de su propio departamento para poder pensar en su trabajo? Sugiere a su amigo Rateau que pensar en su trabajo significa trabajar. Rateau le pregunta: “¿Tu travailles? - C'est tout comme. — ¡Mais tu n'as pas de toile! — Je travaille quand même" (Camus, L'Exil: 140). En efecto, Jonas, en ese periodo de su vida, coloca entre él y los otros la mesa que simboliza el mundo para Arendt. Aquí, la mesa es la buhardilla que le permite estar sólo sin perder la compañía de su querida familia. Se adentra en su fuero interno; reanuda el vínculo con su yo; aprende a ser quien es realmente lo que el narrador, al referirse a Jonas, expresa con la siguiente frase: "il écoutait son propre cœur" (Camus, L'Exil: 138).

El dilema del artista no se resuelve, nos sugiere Camus, con el final de su cuento: la palabra escrita en el cuadro blanco de Jonas, resultado de sus reflexiones, es indescifrable. Resulta ser a un mismo tiempo solitario y solidario. Una sola letra cambiaría todo el sentido, y además, las dos palabras tienen un sentido opuesto. Las dos oposiciones tienen que convivir, tal como Jonás lo hace aislado en su buhardilla y simultáneamente en compañía de sus seres queridos. Su mejor amigo le dice, hablando de su esposa y sus hijos: "Ils vont bien. Ils iraient mieux si tu étais avec eux". Cuando le contesta, Jonas expresa esta ambigüedad así: "Je ne les quitte pas. Dis-leur surtout que je ne les quitte pas" (Camus, L'Exil: 141). En efecto, el pintor había inventado su lugar y se había vuelto un sujeto moral porque se había hecho autónomo, condición indispensable para coexistir en la sociedad. "Jonas écoutait la belle rumeur que font les hommes. De si loin, elle ne contrariait pas cette force joyeuse en lui, son art, ses pensées qu'il ne pouvait pas dire, à jamais silencieuses, mais qui le mettaient au-dessus de toutes choses, dans un air libre et vif' (Camus, L'Exil: 142). Jonas se libera y encuentra la verdad que concierne no sólo el arte sino también a la vida entera. Caerse de su buhardilla es entonces simbólico del encuentro del personaje con su yo, un yo a la vez solitario y solidario.

Según el largo camino del sujeto moral recordado por Giroux, ${ }^{1}$ parece que el personaje de Jonas no ha alcanzado todavía la llave de la felicidad. Sólo acaba de librarse. Le faltan dos etapas que son comprometerse y reconocerse. Concuerdo con Auroy

\footnotetext{
${ }^{1}$ El trayecto del personaje para construirse como sujeto moral sigue los capítulos de la segunda parte del libro, que son: Despertar, Inventarse, Sobrevivir, Librarse, Comprometerse y Reconocerse.
} 
cuando dice que Camus pasa de la soledad de Cristo en los textos del inicio de los años cuarenta a lo que, después, hace de él la figura de la solidaridad humana, vivificada por el amor (Auroy: 442).

\section{El reino de la fraternidad}

En el último cuento de L'Exil et le Royaume, "La pierre qui pousse", el protagonista, d'Arrast, no ha encontrado su lugar entre los suyos, en su sociedad, y entonces la busca en el pueblo de Iguape, en Brasil. Allí encuentra a un cocinero que, para agradecer a Cristo que le ha salvado la vida en el incendio de su nave, le hizo la promesa de traer en su honor una piedra de cincuenta kilos en su espalda durante una larga procesión hacia la iglesia. Sea dicho de paso, esta piedra es la de Sísifo, tan simbólica del absurdo de la vida. A pesar de todo, el cocinero debilitado no llega a su meta y tiene que abandonar la piedra a medio camino. La simpatía inicial de d'Arrast por el cocinero se transforma en una solidaridad activa cuando la carga sobre sus hombros en su lugar, salvando la promesa de su amigo. Sin embargo, no lleva la piedra a la iglesia, sino a la casa del cocinero, entre los miembros de su familia que lo invitan a sentarse entre ellos, en un gesto de fraternidad. "Le frère s'écarta un peu du coq et se tournant à demi vers d'Arrast, sans le regarder, lui montra la place vide: 'Assieds-toi avec nous"' (Camus, L'Exil: 188). De esta manera, d'Arrast descubre la solidaridad que lo liga a los hombres. Al final del cuento, que es también el final de la compilación de cuentos, d'Arrast encuentra su felicidad y su reino. "[...] le bruit des eaux l'emplissait d'un bonheur tumultueux. Les yeux fermés, il saluait joyeusement sa propre force, il saluait une fois de plus, la vie qui recommençait" (Camus, L'Exil: 188). Así, d'Arrast encuentra su paz interior y su felicidad en la solidaridad humana, no en la religión, como lo sugiere su cambio de rumbo de la iglesia a la casa pobre de su amigo. La compilación de cuentos L'Exil et le Royaume muestra que la felicidad de los personajes se concibe únicamente en la tierra.

La otra enseñanza de esta compilación se entiende muy bien a la luz de Giroux. 'L'avènement du sujet et de la vie en tant que soi-même tient dans la rencontre de l'autre soi-même, dans l'expérience de l'amour et de l'amitié sous toutes les formes que peut prendre l'ouverture à l'autre" (Giroux: 130). La otredad es la clave del encuentro con sí mismo. Y la relación con el otro pasa por el amor por él. Éste es otro punto en común entre Camus y Dostoievski. El "hombre ridículo", después de haber rechazado duramente a la miserable niña desesperada porque todo le daba igual y sólo quería suicidarse, descubre la Verdad a través de un sueño. Admira un mundo donde las personas viven en paz, igualdad, armonía y fraternidad. Sentir el amor infinito e incondicional de estos humanos por él y por los elementos de la naturaleza es para él la revelación de la Verdad. Antes de dormirse, el personaje ruso estaba a punto de matarse, pero al despertar, su alma se llenó de vida y plenitud, tal como d'Arrast, al poner la piedra en la casa de los indígenas. Así, en la última página del cuento, el "hombre ridículo" de Dostoievski expresa su felicidad construida por su amor por la humanidad. 
[...] Parce que j'ai vu la vérité, parce que j'ai vu et que je sais que les hommes peuvent être beaux et heureux sans perdre le pouvoir de vivre sur la terre... Ce qui compte: aime ton prochain comme toi-même... tu trouveras tout de suite comment construire. Et pourtant, tout cela, ce n'est rien qu'une vieille vérité qu'on rabâche, qu'on a lue des billions de fois, mais, voilà, elle n'a pas pris racine! 'La conscience de la vie est supérieure à la vie elle-même, la connaissance des lois du bonheur — supérieure au bonheur', voilà ce qu'il faut combattre! Et je combattrai. Et si seulement, tout le monde le voulait, tout se construirait d'un coup.

$[\ldots]$

Quant à la petite fille, je l'ai retrouvée... Et j'irai! J'irai! (57-59).

No cabe duda que el encuentro con la niña le provoca al personaje el despertar de su amor por su prójimo porque siente dolor al escuchar su grito de sufrimiento y, sobre todo, este sueño le ocurre justamente después de escucharlo. Después de su encuentro con ella, el protagonista reflexiona sobre varios problemas morales y metafísicos. Asistimos a la realización del sujeto moral tal como Giroux lo define.

La solidaridad en el combate, simbolizada por la piedra del cocinero transmitida a d'Arrast, o la de Sísifo, nunca concluye. Camus, después de L'Étranger, se compromete totalmente con el combate político durante los acontecimientos de la guerra de Argelia y este compromiso por los hombres se refleja muy bien en su novela La Peste.

En fin, Camus afirma a través de su obra literaria que, a pesar del absurdo que puede ser desesperante, el ser humano debe disfrutar la vida con plenitud y amor porque tiene un deber moral y un compromiso con los otros seres humanos. Para lograrlo, primero tiene que tomar conciencia del absurdo y del mundo en el cual existe, es decir, tiene que despertarse; luego buscar ser fiel a sí mismo y volverse lo que ya es, lo que necesita una gran dosis de soledad para poder encontrar la naturaleza de sus vínculos con los otros, el camino desde la vida marginada hacia la existencia compartida. ¿Y qué mejor medio para alcanzar esta sabiduría que la literatura y el arte en general? Giroux recuerda que el acto de crear es un trabajo de desciframiento, de interpretación del libro interior que lleva dentro el artista (Giroux: 149), trabajo que Jonas y Albert Camus realizan a través de su arte. En su Discours de Suède, Camus afirma que “c'est au moment même où l'artiste choisit de partager le sort de tous qu'il affirme l'individu qu'il est” (54). Según Albert Camus, entonces, la vocación del verdadero arte es reunir a los hombres. ¿Su misión no será, justamente, hacer tomar conciencia a los lectores, retomando las palabras del "hombre ridículo", de que "la conscience de la vie est supérieure à la vie elle-même, la connaissance des lois du bonheur, supérieure au bonheur”?

\section{Obras citadas}

Auroy, Carole. "Jésus-Christ". Dictionnaire Albert Camus. Dir. Jean-Yves GuERIN. París: Bouquins, 2009. Impreso. 
BAISHANSKI, Jacqueline. L'Orient dans la pensée du jeune Camus. L'Étranger, un nouvel évangile? París-Caen: Lettres Modernes Minard, 2002. Impreso.

CAmus, Albert. La caída. Madrid: Debate, 1995. Impreso. . Discours de Suède. París: Gallimard, 1958. Impreso. . L'Exil et le royaume. París: Gallimard, 1957. Impreso. L'Étranger. París: Gallimard, 1942. Impreso.

Dostö̈EvSKI, Fedor. Le Rêve d'un homme ridicule. Un récit fantastique (Journal d'un Écrivain, édition mensuelle, avril 1877, chapitre II). Trad. André MARKOWICZ. Arles: Actes Sud, 1993. Impreso.

GIROUX, Aline. Du personnage romanesque au sujet moral. La littérature comme autre de la philosophie. Montreal: Liber, 2012. Impreso.

Grouix, Pierre. "L'Exil et le Royaume". Dictionnaire Albert Camus. Dir. JeanYves Guerin. París: Bouquins, 2009. Impreso.

MageE, Bryan, dir. Men of Ideas: Some Creators of Contemporary Philosophy. Chapter 14, "Philosophy and Literature: Dialogue with Iris Murdoch". Oxford: Open University Press, 1978. Impreso.

RICEUR, Paul. Soi-même comme un autre. París: Seuil, 1990. Impreso. 
